Discussion Papers in

Economics and Econometrics

\begin{tabular}{|l||}
\hline A MARKOV-SWITCHING VECTOR \\
EQUILIBRIUM CORRECTION MODEL \\
OF THE UK LABOUR MARKET \\
Hans-Martin Krolzig \\
Massimiliano Marcellino \\
Grayham E Mizon \\
No. 0105 \\
\hline
\end{tabular}

This paper is available on our website http://www/soton.ac.uk/ econweb/dp/dp01.html 


\title{
A Markov-Switching Vector Equilibrium Correction Model of the UK Labour Market
}

\author{
Hans-Martin Krolzig \\ Department of Economics and Nuffield College, Oxford. \\ Massimiliano Marcellino \\ Istituto di Economia Politica, Università Bocconi and IGIER \\ and \\ Grayham E. Mizon* \\ Economics Department, University of Southampton
}

30 November 2000

\begin{abstract}
There is a wide literature on the dynamic adjustment of employment and its relationship with the business cycle. Our aim is to propose a statistical model that offers a congruent representation of post-war UK labour market. We use a cointegrated vector autoregressive Markov-switching model where some parameters change according to the phase of the business cycle. Output, employment, labour supply and real earnings are found to have a common cyclical component. The long run dynamics are characterized by two cointegrating vectors: trend-adjusted labour productivity and the labour share. Despite there having been many changes affecting this sector of the UK economy, the Markov-switching vector-equilibrium-correction model with three regimes representing recession, growth and high growth provides a good characterization of the sample data over the period 1966(3)-1993(1) In an out-of-sample forecast experiment over the period 1991(2)-1993(1) it beats linear and non-linear model alternatives. The results of an impulse-response analysis highlight the dangers of using VARs when the constancy of the estimated coefficients has not been established.

Keywords: Business Cycles, Employment, Impulse-Response Analysis, Cointegration, Regime Shifts, Markov Switching.
\end{abstract}

JEL classification: E32, E37, C32, E24

\footnotetext{
* Preliminary: please do not quote without the authors' permission. Financial support from the UK Economic and Social Research Council under grant L116251015 is gratefully acknowledged by the first and third author.
} 


\section{Introduction}

There have been numerous studies analyzing systems characterizing the time series relationships between wages, prices, productivity and unemployment in the UK (recent examples include Clements and Mizon, 1991, Mizon, 1995, and Marcellino and Mizon, 2000a). These studies, using data from the 1960s to the 1990s, have found evidence of structural change and have modelled it via split-sample analysis with a single break occurring in 1979, possibly with additional dummy variables to capture the effects of other institutional changes in the UK labour market.

As an alternative to this deterministic approach to structural change and regime shifts, in this paper we develop a small model of the UK labour market using a multivariate Markov-switching vector equilibrium correction model (MS-VECM). This methodology is well suited to model the domestic and international cyclical swings that affected the UK economy, and it allows for changing relationships among the labour market variables across different phases of the business cycle. The results we obtain are easily interpretable both from an economic and from an econometric perspective. First, we find two equilibrium relationships that are interpreted as measures of the output gap and of the labour share, which have constant coefficients, though regime shifts in their means, across the whole sample period. Second, switches in the regimes are closely related to changes in the phases of the UK business cycle: the first regime is associated with recessions, the second and the third regimes with periods of normal and sustained growth respectively. Third, the MS-VECM provides a congruent statistical representation for the data, and the restrictions that lead to a standard linear model are strongly rejected. Fourth, the MS-VECM performs well in forecasting.

Another important characteristic of our MS-VECM is that the contemporaneous covariance matrix of the residuals is also regime switching, and substantial differences across regimes emerge. Hence, standard impulse response analysis is likely to lead to severely biased results. We show that this is indeed the case, and derive the appropriate response functions for each regime. Moreover, the standard approach focuses on the response of the system to Gaussian innovations, even though other shocks could affect the system. In particular, changes in the phase of the cycle is what some economists have in mind when they refer to 'cyclical shocks', namely, investigating the dynamics of some variables in the transition from boom to bust, or vice versa. Within our framework, we also present response functions for this type of shock.

The structure of the paper is the following. Section 2 describes the data and summarises some of the major changes that have taken place in the UK labour market between 1965 and 1993. The specification of a Vector Equilibrium Correction Model (VECM) with non-constant parameters is described in section 3 , and the particular form of the MS-VECM used in this paper is presented in section 4, which also contains the empirical results: firstly for the cointegrated VAR in section 4.1, and then for the MSVECM in section 4.2. The forecasting performance of the alternative forms of model is evaluated in section 5. Section 6 contains a comparison of the impulse response functions of the alternative models, and illustrates the susceptability of such analyses to non-constant parameters. Section 7 summarizes and provides conclusions.

\section{The Data}

The seasonally adjusted quarterly data for the UK are based on the dataset used in Clements and Mizon (1991) as extended to cover the period 1965(1)-1993(1) in Mizon (1995) and Marcellino and Mizon (2000a). The original sources for these data are "Economic Trends" and "Monthly Digest of Statistics" published by the UK Office of National Statistics. 
The output variable, $y_{t}$, is the log of total constant price GDP. Employment and the labour force, $n_{t}$ and $n s_{t}$, are the logs of the number of employees and the total labour force in the whole economy. The earnings variable, $e_{t}$, is the $\log$ of the ratio of wages and salaries to the number of employees multiplied by the average weekly hours of work in the manufacturing sector. The price variable, $p_{t}$, is the $\log$ of the retail price index. The real wage, $w p_{t}$, is given by the log of real earnings $\left(w p_{t}=e_{t}-p_{t}\right)$. This broad definition of the real wage is in line with earlier studies by Hall (1986) and Hall (1989). For the following analysis, it is convenient to define two more variables. First, a measure of average labour productivity, given by the log of output per employee, $y_{t}-n_{t}$. Sargan (1964) in his model of wage determination used this measure of labour productivity, Hall and Henry (1987) in their study of alternative wage models provided evidence in favour of this measure rather than the capital-labour ratio, and Marcellino and Mizon (2000b) interpreted the deviation of this variable from sample trend as the output gap in their analysis of the labour sector of the Italian economy. Second, the log labour share, defined as share $_{t}=w p_{t}+n_{t}-y_{t}$.
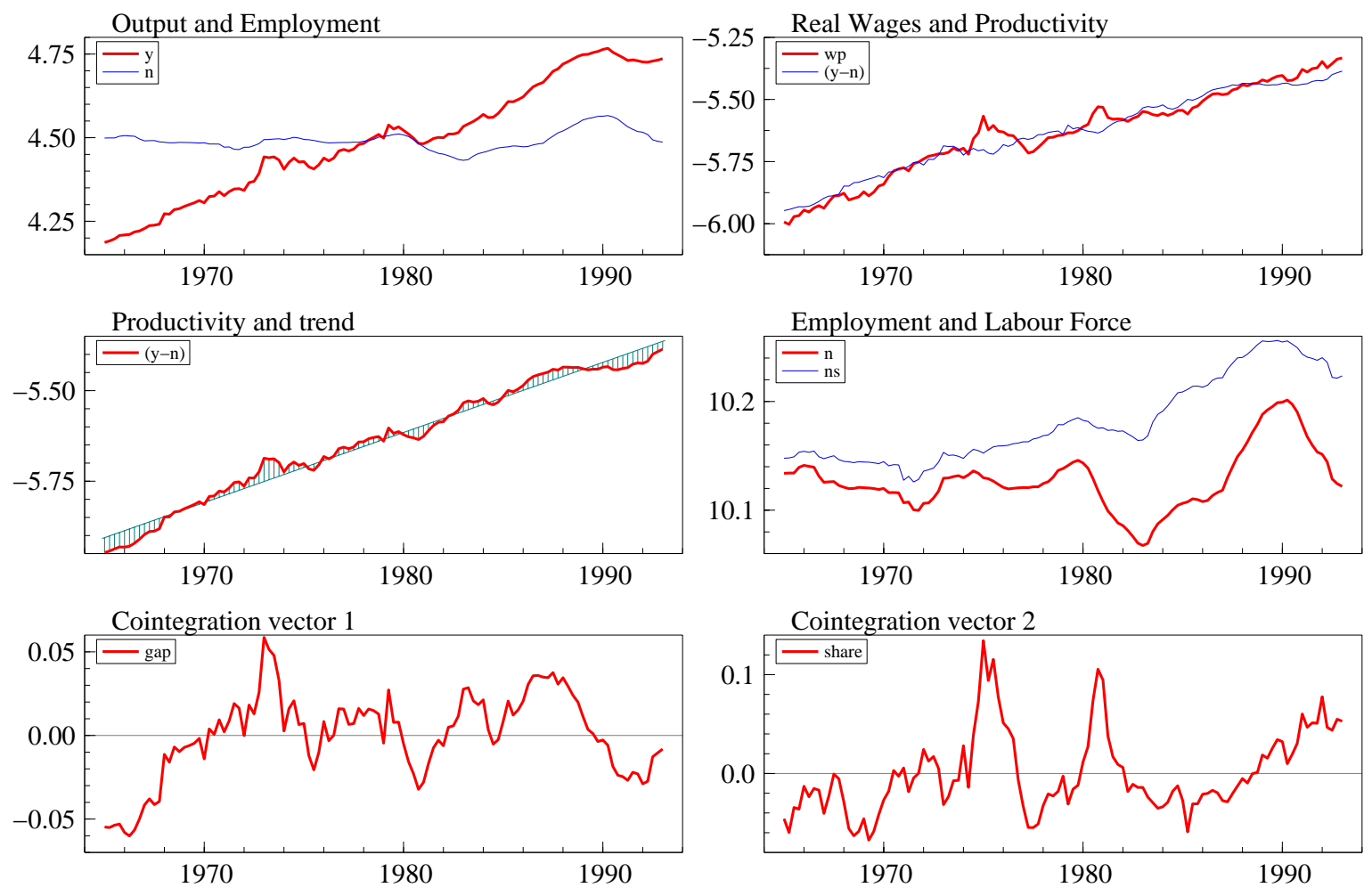

Figure 1 The variables under analysis and the restricted equilibria.

The variables are graphed in the first four panels of Figure 1. Among the most striking features, we note the similar behaviour of real wages and productivity (panel 2 in which the variables have been scaled to match their means), and the largely stationary nature of the labour share (panel 6). Deviations of productivity from a linear trend also appear to be stationary (panels 3 and 5).

Notable events affecting the UK labour market in the sample period include the following. The big increase in real wages in 1975 associated with the ending of a period of statutory wage and price control, and the decline in productivity in 1984 mainly related to the effects of the Miners' Strike, which began in 1984(2). Unemployment has also increased strongly throughout the sample period, with some business cycle fluctuations. The decline in 1966 is related to the introduction of the "selective employment tax", which aimed to increase employment in manufacturing industries, though it was subsequently 
reduced by 50\% in 1971. The substantial reductions in unemployment in 1974 and 1988/89 were mainly the delayed consequences of pre-election expansionary policies. 1974 was a turbulent year in the UK labour market with numerous strikes and the 3 Day Week restrictions leading to a change of government, followed by a strong increase in unemployment. The increase in unemployment in the early and late 1980s is instead related to the tight monetary policy adopted to reduce the aggregate rate of inflation, and the recession induced by this policy. Throughout the sample period there was an increase in female labour participation, which in turn led to more part-time working. There was also a major policy regime shift in late 1979 from broadly Keynesian full-employment to monetarist anti-inflation policies. Hence difficulties are likely to be experienced in attempting to develop VAR models with constant parameters for a small number of labour market variables.

\section{Modelling Cointegrated Systems with Non-Constant Parameters}

Clements and Hendry (1999) showed that unmodelled shifts in deterministic variables, such as intercepts and trends, are the major cause of forecast failure in econometric models, and that these shifts are detectable by conventional tests for parameter constancy such as those in Chow (1960). On the other hand, changes in short run adjustment coefficients and in the equilibrium coefficients are difficult to detect. Hence, we focus here on changes in the mean growth rates of the $N$ variables $\mathbf{x}_{t}$ and in the means of the $r$ equilibrium relationships $\beta^{\prime} \mathbf{x}_{t}$. In particular, we consider a VECM for the I (1) variables $\mathbf{x}_{t}$ with intercept shifts introduced:

$$
\Delta \mathbf{x}_{t}=\boldsymbol{\nu}\left(s_{t}\right)+\alpha \beta^{\prime} \mathbf{x}_{t-1}+\mathbf{u}_{t}, \quad \mathbf{u}_{t} \mid s_{t} \sim \operatorname{NID}(0, \Sigma),
$$

where $s_{t}$ denotes the unobservable regime indicator variable $s_{t} \in\{1, \cdots, M\}, \alpha$ and $\beta$ are $N \times r$ matrices of rank $r$, and for simplicity only one period lags are introduced into the system and the error covariance matrix is assumed constant. Note that the intercept $\nu$ is a function of the underlying state:

$$
\boldsymbol{\nu}\left(s_{t}\right)=\boldsymbol{\nu}_{s_{t}}=\left\{\begin{array}{cc}
\boldsymbol{\nu}_{1} & \text { if } s_{t}=1 \\
& \vdots \\
\boldsymbol{\nu}_{M} & \text { if } s_{t}=M .
\end{array}\right.
$$

and can be decomposed into:

$$
\begin{aligned}
\boldsymbol{\nu}\left(s_{t}\right) & =\beta_{\perp}\left(\alpha_{\perp}^{\prime} \beta_{\perp}\right)^{-1} \alpha_{\perp}^{\prime} \boldsymbol{\nu}\left(s_{t}\right)+\alpha\left(\beta^{\prime} \alpha\right)^{-1} \beta^{\prime} \boldsymbol{\nu}\left(s_{t}\right) \\
& =\beta_{\perp} \boldsymbol{\delta}^{*}\left(s_{t}\right)+\alpha \boldsymbol{\mu}\left(s_{t}\right)
\end{aligned}
$$

when $\alpha_{\perp}$ and $\beta_{\perp}$ are $N \times(N-r)$ matrices such that $\alpha_{\perp}^{\prime} \alpha=0$ and $\beta_{\perp}^{\prime} \beta=0$. This means that there are $(N-r)$ linearly independent but state-dependent drifts $\delta^{*}\left(s_{t}\right)$, and $r$ linearly independent but state-dependent equilibrium means $\boldsymbol{\mu}\left(s_{t}\right)$ in the system. Hence, the process (1) can be represented as:

$$
\Delta \mathbf{x}_{t}-\beta_{\perp} \boldsymbol{\delta}^{*}\left(s_{t}\right)=\alpha\left(\beta^{\prime} \mathbf{x}_{t-1}-\boldsymbol{\mu}\left(s_{t}\right)\right)+\mathbf{u}_{t}, \quad \mathbf{u}_{t} \mid s_{t} \sim \operatorname{NID}(0, \Sigma) .
$$

In (3), both $\Delta \mathbf{x}_{t}$ and $\beta^{\prime} \mathbf{x}_{t}$ are expressed as deviations about their regime- and time-dependent means, $\beta_{\perp} \boldsymbol{\delta}^{*}\left(s_{t}\right)$ and $\boldsymbol{\mu}\left(s_{t}\right)$ respectively. Hence, each regime is characterized by an attractor of the system defined by the equilibrium value of the cointegration vector and the drift. Such a formulation is closely related to the notion of multiple equilibria in dynamic economic theory - see e.g. Cooper and John, 1988. 
Two implications of the condition $\mathrm{E}\left[\Delta \mathrm{x}_{t} \mid s_{t}\right]=\beta_{\perp} \boldsymbol{\delta}^{*}\left(s_{t}\right)$ are worth noting. First, the mean growth rate of the equilibria $\beta^{\prime} \mathbf{x}_{t}$ is zero, i.e.,

$$
\mathrm{E}\left[\Delta\left(\beta^{\prime} \mathbf{x}_{t} \mid s_{t}\right)\right]=\mathrm{E}\left[\beta^{\prime} \Delta \mathbf{x}_{t} \mid s_{t}\right]=\beta^{\prime} \mathrm{E}\left[\Delta \mathbf{x}_{t} \mid s_{t}\right]=\beta^{\prime} \beta_{\perp} \boldsymbol{\delta}^{*}\left(s_{t}\right)=\mathbf{0}
$$

Second, if we interpret $\beta_{\perp}^{\prime} \mathbf{x}_{t}$ as stochastic trends in the system, then their mean growth rate is given by $\boldsymbol{\delta}^{*}\left(s_{t}\right)$, i.e.,

$$
\mathrm{E}\left[\Delta\left(\beta_{\perp}^{\prime} \mathbf{x}_{t} \mid s_{t}\right)\right]=\mathrm{E}\left[\beta_{\perp}^{\prime} \Delta \mathbf{x}_{t} \mid s_{t}\right]=\beta_{\perp}^{\prime} \mathrm{E}\left[\Delta \mathbf{x}_{t} \mid s_{t}\right]=\beta_{\perp}^{\prime} \beta_{\perp} \boldsymbol{\delta}^{*}\left(s_{t}\right)=\boldsymbol{\delta}^{*}\left(s_{t}\right)
$$

Considering instead the stochastic trends represented by $\alpha_{\perp}^{\prime} \mathbf{x}_{t}$, as in Gonzalo and Granger (1995), then their expected change is

$$
\mathrm{E}\left[\Delta\left(\alpha_{\perp}^{\prime} \mathbf{x}_{t} \mid s_{t}\right)\right]=\mathrm{E}\left[\alpha_{\perp}^{\prime} \Delta \mathbf{x}_{t} \mid s_{t}\right]=\alpha_{\perp}^{\prime} \mathrm{E}\left[\Delta \mathbf{x}_{t} \mid s_{t}\right]=\alpha_{\perp}^{\prime} \beta_{\perp} \boldsymbol{\delta}^{*}\left(s_{t}\right)=\alpha_{\perp}^{\prime} \boldsymbol{\nu}\left(s_{t}\right)
$$

When the changes in $\boldsymbol{\nu}\left(s_{t}\right)$ are due to a small number of deterministic shifts at known dates, their effects can be captured by including in the model an appropriate set of dummy variables. This is a common approach in empirical modelling of macroeconomic time series, and Clements and Mizon (1991) provide an example in the context of a small econometric model of the UK labour market. A similar approach can be adopted when there are changes in $\alpha$ and $\beta$ as well as the intercepts. However, in this latter case, when the sub-samples permit, a valuable alternative is to conduct a split sample analysis of the data. Again with reference to the UK labour market, Marcellino and Mizon (2000a) distinguish between the pre- and post-Thatcher period, finding evidence of substantial differences between the two sub-periods.

When the regime shifts are stochastic rather than deterministic both previous approaches can lead to biased, or at least inefficient, results. In this case, it is possible to enlarge the system by adding variables that are related to the regime shifts, such as policy variables, energy and raw material prices, and demographic and social indicators. Yet, it is difficult to jointly model the resulting enlarged set of variables, and conditioning on the regime shift related variables may not be valid and even if it were would not solve the forecasting problem (see Marcellino and Mizon, 2000b for more details).

Therefore, a multivariate generalization of the univariate Markov- switching model originally proposed by Hamilton (1989) provides a viable alternative. The general idea behind the class of MS models is that the some of the parameters depend upon a stochastic, unobservable regime indicator variable $s_{t} \in\{1, \ldots, M\}$. The stochastic process for generating the unobservable regimes is an ergodic Markov chain, defined by the transition probabilities:

$$
p_{i j}=\operatorname{Pr}\left(s_{t+1}=j \mid s_{t}=i\right), \quad \sum_{j=1}^{M} p_{i j}=1 \quad \forall i, j \in\{1, \ldots, M\} .
$$

By inferring the probabilities of the unobserved regimes conditional on an available information set, it is then possible to reconstruct the regimes. For an ergodic Markov chain, regime shifts are persistent if $p_{i j} \neq p_{i i}$ for some $i \neq j$, but not permanent if $p_{i i} \neq 1$ for all $i$. Further, (3) and (5) define a MSI-VECM (see Krolzig, 1997) when MSI refers to a Markov-switching intercept. The MSI-VECM exhibits equilibrium as well as error correction mechanisms: in each regime disequilibria are adjusted by the vector equilibrium correction mechanism; since the regimes themselves are generated by stationary, irreducible Markov chain; errors arising from regime shifts themselves are corrected towards the stationary distribution of the regimes. 
Markov-switching models of multiple time series (see Krolzig, 1997, for an overview) provide a powerful statistical tool for extracting the common component from a group of economic time series representing the business cycle. In their investigation of the interaction of the UK business cycle with changes in the industrial structure of the UK economy during the last three decades, Krolzig and Sensier (2000) propose a Markov-switching vector equilibrium correction model with three regimes representing recession, normal growth and high growth. In their model the regime shifts simultaneously affect the common growth rate and the sectoral equilibrium allocation of industrial production identifying a common cycle which is closely related to traditional datings of the UK business cycle. Hence, an MSIVECM appears to be a promising alternative specification for a small model of the UK labour market.

\section{An MSIH-VECM for Real Wages, Output, and Employment}

Following Krolzig (1997) we adopt a Markov-switching vector equilibrium correction model with shifts in the drift $\boldsymbol{\delta}\left(s_{t}\right)$ and in the equilibrium mean $\boldsymbol{\mu}\left(s_{t}\right)$ :

$$
\Delta \mathbf{x}_{t}-\boldsymbol{\delta}\left(s_{t}\right)=\alpha\left(\beta^{\prime} \mathbf{x}_{t-1}-\boldsymbol{\mu}\left(s_{t}\right)-\gamma(t-1)\right)+\sum_{k=1}^{p-1} \Gamma_{k}\left(\Delta \mathbf{x}_{t-k}-\boldsymbol{\delta}\left(s_{t}\right)\right)+\mathbf{u}_{t},
$$

and the error variance is allowed to change across states $\mathbf{u}_{t} \mid s_{t} \sim \operatorname{NID}\left(\mathbf{0}, \Sigma\left(s_{t}\right)\right)$. Krolzig (1997) denotes this model by MSIH-VECM, where the $\mathrm{H}$ refers to heteroskedasticity in the error process. Note that $\beta^{\prime} \boldsymbol{\delta}\left(s_{t}\right)=0$ since $\mathrm{E}\left[\Delta \mathbf{x}_{t} \mid s_{t}\right]=\boldsymbol{\delta}\left(s_{t}\right)=\beta_{\perp} \boldsymbol{\delta}^{*}\left(s_{t}\right)$ from (4). The vector $\mathbf{x}_{t}$ includes output ( $\left.y_{t}\right)$, real wages $\left(w p_{t}\right)$, employment $\left(n_{t}\right)$, and the labour force $\left(n s_{t}\right)$, where the latter is included in the system to capture some changes in demographic and social conditions, such as different birth rates and female participation rates. As discussed in section 2, other variables might affect and modify the relationships between $y_{t}, w p_{t}$ and $n_{t}$. Within the framework of the MSIH-VECM in (6) their effects are captured by $\boldsymbol{\delta}\left(s_{t}\right), \boldsymbol{\mu}\left(s_{t}\right)$ and $\Sigma\left(s_{t}\right)$. As in (5), the unobservable regime variable $s_{t}$ is governed by a Markov chain with a finite number of states ( 3 in our case), defined by the transition probabilities $p_{i j}$.

Each regime, $m$, is associated with a particular attractor $\left(\boldsymbol{\mu}_{m}, \boldsymbol{\delta}_{m}\right)$. Regime shifts in $\boldsymbol{\delta}_{m}$ are interpreted as changes in the state of the business cycle, regime shifts in $\boldsymbol{\mu}_{m}$ as changes in the equilibrium mean $\boldsymbol{\mu}\left(s_{t}\right)$. Note that changes in the equilibrium mean's deterministic trend, $\gamma t$, are not considered. In the results presented below we find two equilibrium relationships: one indicating that the log labour share is stationarity; and the other that the log average labour productivity is trend stationary. Hence, changes in $\boldsymbol{\mu}_{m}$ reflect changes in equilibrium productivity (trend adjusted) and in the equilibrium labour share.

We now estimate the MSIH-VECM in (6) using the data described in section 2. The maximum likelihood (ML) estimation of the model is based on a version of the Expectation-Maximization (EM) algorithm discussed in Hamilton (1990) and Krolzig (1997). All the computations reported in this paper were carried out with the MSVAR class for Ox, see Krolzig (1998a) and Doornik (1999). The estimation method used is the two-stage procedure suggested by Krolzig (1996): first we investigate the cointegration properties of the system; then we present the results from estimating the MSIH-VECM.

\subsection{Cointegration Analysis}

The cointegration properties of the data are studied within a linear VAR representation using the maximum likelihood method of Johansen (1995) for the sample period 1966(2) to 1993(1). Thus the VAR( $p$ ) is here considered as an approximation of the VARMA representation of an MSI-VAR process. Starting with a $\operatorname{VAR}(6)$ and deleting lags which were not significant according to a likelihood ratio (LR) test, 
led us to a VAR(5). The Johansen procedure for cointegration analysis is then applied to the VECM representation of a VAR with five lags, a constant, and a linear trend restricted to lie in the cointegration space:

$$
\Delta \mathbf{x}_{t}=\boldsymbol{\nu}+\sum_{k=1}^{4} \Gamma_{k} \Delta \mathbf{x}_{t-k}+\alpha\left(\beta^{\prime} \mathbf{x}_{t-1}-\gamma(t-1)\right)+\mathbf{u}_{t}
$$

Table 1 Johansen Cointegration Likelihood Ratio Test.

\begin{tabular}{cccccccc}
\hline \hline & & \multicolumn{3}{c}{ Maximal Eigenvalue Test } & \multicolumn{3}{c}{ Trace Test } \\
\hline eigenvalue & Ho:rank $=r$ & $-T \log (1-\mu)$ & $T-n m$ & $95 \%$ & $-T \sum \log (\cdot)$ & $T-n m$ & $95 \%$ \\
\hline 0.2570 & $r=0$ & $32.09^{*}$ & 26.14 & 31.5 & $81.20^{* *}$ & $66.17^{*}$ & 63.0 \\
0.1889 & $r \leq 1$ & 22.61 & 18.42 & 25.5 & $49.12^{* *}$ & 40.02 & 42.4 \\
0.1247 & $r \leq 2$ & 14.39 & 11.72 & 19.0 & $26.51^{*}$ & 21.60 & 25.3 \\
0.1062 & $r \leq 3$ & 12.12 & 9.88 & 12.3 & 12.12 & 9.88 & 12.3 \\
\hline \hline
\end{tabular}

** Significant at $1 \%$ level, * Significant at $5 \%$ level.

The results of the cointegration tests are shown in Table 1 with the trace and maximal eigenvalue test statistics. On the basis of these results and the values of the eigenvalues, we select $r=2$. There is no indication of remaining autocorrelation in the errors (vector AR 1-5 test: $F(80,250)=0.87$ with a p-value of 0.76 ) but there is strong evidence of non-normality in the residuals (vector normality test $\chi^{2}(8)=58.16$ with a p-value of 0.00$)$. The latter is most likely the result of the many outliers present in the estimated VAR. Although this can result in under-estimation of cointegrating rank, our subsequent results which allow for Markov switching between three separate regimes suggest that this is not case.

We then identify the cointegrating vectors by applying a set of non-rejected restrictions, the LR test for which is $\chi^{2}(9)=11.90$ with a p-value of 0.22 . The resulting equilibria are graphed in the last two panels of Figure 1 above. The first one is trend-adjusted productivity which Marcellino and Mizon (2000b) interpreted as a measure of the output gap:

$$
g a p_{t}=y_{t}-n_{t}-\underset{(0.0001)}{0.0046} t
$$

Productivity grew at an average rate of about $2 \%$ per year, which reflects accumulation of physical and human capital as well as technical progress, and deviations from this trend are stationary. The second equilibrium is the log labour share:

$$
\operatorname{share}_{t}=w p_{t}+n_{t}-y_{t}
$$

Combining (8) and (9), we can also infer that the real wage, $w p_{t}$, appears to be stationary around a linear trend.

These results are coherent with those reported in Clements and Mizon (1991), though the latter used a slightly different set of variables - including unemployment and inflation, but excluding employment and the labour force. Yet, they also found that an equilibrium involving real wages and productivity with coefficients $(1,-1)$, as in (9), and unemployment with a very low coefficient (0.06) in this relationship. They discussed the existence of another equilibrium that related positively productivity and unemployment, but they did not use it since its economic interpretation is problematic. Marcellino and Mizon (2000a) also found a positive relationship between $w p_{t}$ and $y_{t}-n_{t}$, both before and after 1980, but the homogeneity restriction was rejected in the pre-1980 sub-sample. Their second equilibrium relationship had a Phillips curve interpretation. Krolzig and Toro (1998) analyze output and employment data for the US over the period 1962-1997, and they also find an equilibrium relationship as in (8), but with an 
higher coefficient for the trend. Hence, we conclude that our results on the equilibria are in agreement with other studies, and quite reasonable from an economic point of view.

Equation (10) reports the estimated VECM, where the estimated lag coefficients and constant have been omitted for simplicity. The equilibrium adjustment is characterized by strong negative reactions of real wages and employment to the labour share (whose peaks coincide with the 1974 and 1982 recessions). Moreover, increases in the trend-adjusted labour productivity cause equal shifts in labour supply and demand, thus leaving unemployment unchanged:

$$
\begin{aligned}
& \widehat{\Delta w p}_{t}=\underset{(0.057)}{-0.22} \text { share }_{t-1}, \\
& \widehat{\Delta y}_{t}=\underset{(0.039)}{-0.07 \text { share }_{t-1},} \\
& \widehat{\Delta n_{t}}=\widehat{\Delta n} s_{t}=\underset{(0.012)}{-0.023 \text { share }_{t-1}}+\underset{(0.017)}{0.07} \text { gap }_{t-1} .
\end{aligned}
$$

\subsection{The MSIH-VECM}

The cointegration results from the last section are now used in the second stage of our analysis. We adopt an MSIH-VECM with 3 regimes and 4 lags (MSIH(3)-VECM(4)) model, with shifts in the intercept $\nu$ and the error variance $\Sigma$. Four 4 lags is the outcome of AIC model selection procedures for the lag length $p$, which is coherent with the result for the VAR in levels, while the number of regimes is fixed a priori, with the aim of capturing periods of low, normal, and high growth. Hence, the resulting model is

$$
\Delta \mathbf{x}_{t}=\boldsymbol{\nu}\left(s_{t}\right)+\alpha\left(\beta^{\prime} \mathbf{x}_{t-1}-\gamma(t-1)\right)+\sum_{k=1}^{4} \Gamma_{k} \Delta \mathbf{x}_{t-k}+\mathbf{u}_{t}
$$

where $\mathbf{u}_{t} \mid s_{t} \sim \operatorname{NID}\left(\mathbf{0}, \Sigma\left(s_{t}\right)\right)$.

The estimated parameters of the MSIH(3)-VECM(4) model (11) using data from 1966(3) to 1993(1) are presented in Table 4 . The transition matrix is given by

$$
\mathbf{P}=\left[\begin{array}{lll}
0.8081 & 0.0606 & 0.0599 \\
0.1516 & 0.8749 & 0.1220 \\
0.0403 & 0.0645 & 0.8181
\end{array}\right]
$$

where $p_{i j}=\operatorname{Pr}\left(s_{t}=i \mid s_{t-1}=j\right)$. The regimes are persistent with the estimated duration of recessions being one and a half years:

Table 2 Persistence of Regimes.

\begin{tabular}{lccc}
\hline \hline & Ergodic Probability & Duration & Observations \\
\hline Regime 1 & 0.2394 & 5.21 & 25.7 \\
Regime 2 & 0.5224 & 8.00 & 53.0 \\
Regime 3 & 0.2382 & 5.50 & 28.3 \\
\hline \hline
\end{tabular}

The resulting regime probabilities are given in Figure 2: Regime 1 depicts very clearly the recessions of 1971, 1974, 1980-82 and 1991-92, whilst regime 3 characterizes high-growth episodes - Regime 2 represents by default 'normal' growth.

Table 3 reports the results of Wald specification tests regarding the significance of the regime shifts in the first moment of the system and the individual variables, respectively. Under the null hypothesis of $\boldsymbol{\nu}_{1}=\boldsymbol{\nu}_{2}=\boldsymbol{\nu}_{3}$ etc., the unrestricted regime-dependent variances ensure the statistical identification 
Table 3 Wald specification tests.

\begin{tabular}{crrrrrc}
\hline \hline Null hypothesis & \multicolumn{1}{c}{ Test statistic } & $\Delta y_{t}$ & $\Delta w p_{t}$ & $\Delta n_{t}$ & $\Delta n s_{t}$ & System \\
\hline$\nu_{1}=\nu_{2}$ & $\chi^{2}(1)$ & $48.94[0.0000]$ & $0.40[0.5262]$ & $47.84[0.0000]$ & $29.42[0.0000]$ & $\chi^{2}(4)=97.79[0.0000]$ \\
$\nu_{2}=\nu_{3}$ & $\chi^{2}(1)$ & $1.56[0.2120]$ & $0.02[0.9025]$ & $24.35[0.0000]$ & $22.12[0.0000]$ & $\chi^{2}(4)=25.56[0.0000]$ \\
$\nu_{1}=\nu_{2}=\nu_{3}$ & $\chi^{2}(2)$ & $58.16[0.0000]$ & $0.45[0.8000]$ & $77.21[0.0000]$ & $51.80[0.0000]$ & $\chi^{2}(8)=147.68[0.0000]$ \\
\hline \hline
\end{tabular}

Note: The numbers in brackets represent the marginal significance level of Wald test statistic.

The regime-identifying assumption of the system test is that $\Sigma_{1} \neq \Sigma_{2} \neq \Sigma_{3}$.
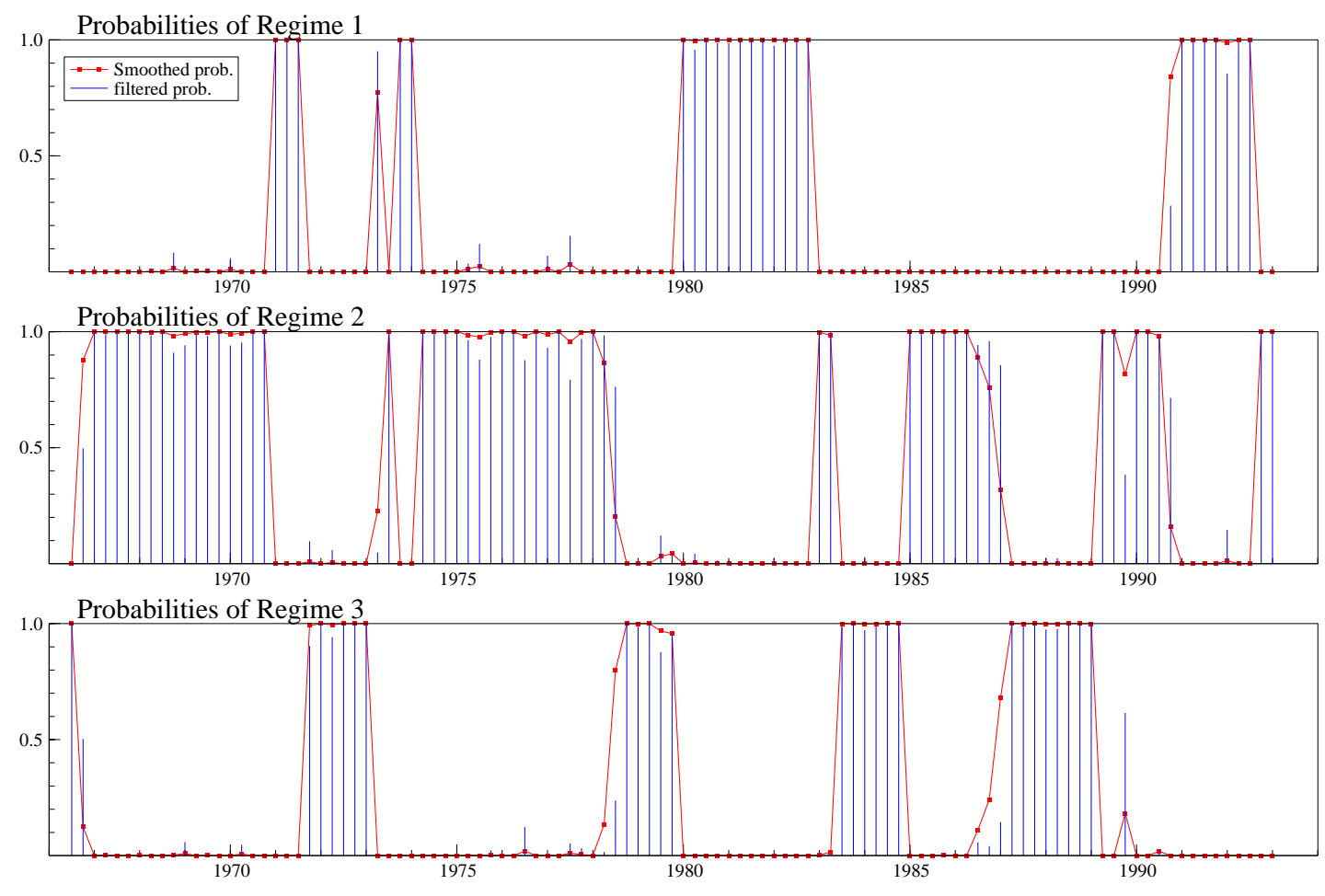

Figure 2 Regime probabilities of the MSIH(3)-VECM(4) model.

of the model under the null hypothesis. The tests are nuisance parameter free so that classical likelihood theory can be invoked, and the asymptotic null distribution of the Wald test is $\chi^{2}(q)$ where $q$ is the number of linearly independent restrictions. The regime-shifts in mean growth rates of the system are statistically highly significant. There is not only strong support for recurring recessions and expansions, but also for the presence of a third regime. Running tests for the equations of the system separately helps to characterize the regimes: In the case of recessions (regime 1) versus normal expansions (regime 2), the test hypothesis $\nu_{k 1}=\nu_{k 2}$ can very strongly rejected be for $\Delta y_{t}, \Delta n_{t}$ and $\Delta n s_{t}$. Comparing the second and the third regime, there is significant change in the mean of $\Delta n_{t}$ and $\Delta n s_{t}$ while $\Delta y_{t}$ faces the same mean growth. As $y_{t}$ and $n_{t}$ are cointegrated, shifts from regime 2 to 3 will cause strong dynamic adjustments leading to 'boom and burst' episodes (see Figure 9). Finally it is worth noting that real wage growth is not directly affected by the regime shifts.

¿From Table 4 it is clear that not only are the estimated intercepts $\boldsymbol{\nu}\left(s_{t}\right)$ different across regimes, but there are also changes in $\Sigma\left(s_{t}\right)$ - note in particular the changes in $\operatorname{cov}\left(u_{\Delta y}, u_{\Delta w p}\right)$. This suggests that the correlations between the variables, conditional on the past, differ across regimes, and so the use of a constant parameter VECM could lead to severely misleading results. A likelihood ratio test of the linear 
Table 4 ML Estimation Results for the MSIH(3)-VECM(4) Model, 1966 (3) - 1993 (1).

\begin{tabular}{|c|c|c|c|c|}
\hline & $\Delta y_{t}$ & $\Delta w p_{t}$ & $\Delta n_{t}$ & $\overline{\Delta n s_{t}}$ \\
\hline \multicolumn{5}{|c|}{ Regime-dependent intercepts $\left(\times 10^{-2}\right)$} \\
\hline$\nu_{1}$ & $-0.5536(0.2091)$ & $1.4601(0.3947)$ & $-0.4355(0.0730)$ & $-0.3392(0.0822)$ \\
\hline$\nu_{2}$ & $0.7733(0.2040)$ & $1.1814(0.3621)$ & $0.0384(0.0460)$ & $0.0936(0.0363)$ \\
\hline$\nu_{3}$ & $1.2063(0.3330)$ & $1.2226(0.3027)$ & $0.4132(0.0752)$ & $0.4346(0.0728)$ \\
\hline \multicolumn{5}{|c|}{ Short-run dynamics } \\
\hline$\Delta y_{t-1}$ & $-0.1462(0.0768)$ & $-0.1918(0.1071)$ & $-0.0116(0.0241)$ & $-0.0534(0.0209)$ \\
\hline$\Delta y_{t-2}$ & $0.0207(0.1013)$ & $-0.3312(0.1186)$ & $-0.0351(0.0252)$ & $-0.0636(0.0210)$ \\
\hline$\Delta y_{t-3}$ & $0.0863(0.0874)$ & $-0.3550(0.1210)$ & $0.0250(0.0232)$ & $0.0063(0.0198)$ \\
\hline$\Delta y_{t-4}$ & $-0.0422(0.0770)$ & $-0.2300(0.1334)$ & $-0.0078(0.0226)$ & $-0.0047(0.0194)$ \\
\hline$\Delta w p_{t-1}$ & $-0.1405(0.0344)$ & $0.0683(0.0848)$ & $-0.0229(0.0114)$ & $-0.0093(0.0097)$ \\
\hline$\Delta w p_{t-2}$ & $0.0288(0.0297)$ & $0.2295(0.0686)$ & $-0.0023(0.0109)$ & $-0.0035(0.0093)$ \\
\hline$\Delta w p_{t-3}$ & $0.0981(0.0350)$ & $-0.2586(0.0674)$ & $0.0194(0.0111)$ & $0.0141(0.0096)$ \\
\hline$\Delta w p_{t-4}$ & $0.0463(0.0347)$ & $-0.0298(0.0697)$ & $0.0145(0.0116)$ & $0.0203(0.0102)$ \\
\hline$\Delta n_{t-1}$ & $-0.3996(0.5924)$ & $0.5700(0.6594)$ & $0.7293(0.1778)$ & $0.1973(0.1598)$ \\
\hline$\Delta n_{t-2}$ & $-0.3795(0.5691)$ & $-1.3133(0.8792)$ & $-0.2724(0.2096)$ & $-0.4471(0.1893)$ \\
\hline$\Delta n_{t-3}$ & $1.2930(0.4928)$ & $3.4385(0.6921)$ & $-0.3791(0.2157)$ & $-0.4189(0.1936)$ \\
\hline$\Delta n_{t-4}$ & $-1.7589(0.3367)$ & $-1.4595(0.4994)$ & $0.2285(0.1480)$ & $0.2988(0.1384)$ \\
\hline$\Delta n s_{t-1}$ & $0.1236(0.5238)$ & $0.7290(0.6716)$ & $-0.6393(0.1732)$ & $-0.2560(0.1586)$ \\
\hline$\Delta n s_{t-2}$ & $0.0679(0.4756)$ & $0.5123(0.8696)$ & $0.0606(0.1884)$ & $0.2519(0.1711)$ \\
\hline$\Delta n s_{t-3}$ & $-1.0537(0.4836)$ & $-3.2259(0.6159)$ & $0.3930(0.1893)$ & $0.4423(0.1707)$ \\
\hline$\Delta n s_{t-4}$ & $0.2032(0.4124)$ & $0.2383(0.4783)$ & $-0.2355(0.1401)$ & $-0.1192(0.1333)$ \\
\hline \multicolumn{5}{|c|}{ Equilibrium correction } \\
\hline share $_{t-1}$ & $-0.0665(0.0263)$ & $-0.2104(0.0460)$ & $-0.0122(0.0068)$ & $-0.0092(0.0055)$ \\
\hline$g a p_{t-1}$ & $0.0692(0.0479)$ & $-0.1355(0.0548)$ & $0.0903(0.0120)$ & $0.0871(0.0102)$ \\
\hline \multicolumn{5}{|c|}{ Regime 1: correlation } \\
\hline$\Delta y_{t}$ & 1.0000 & -0.5611 & 0.1083 & 0.3320 \\
\hline$\Delta w p_{t}$ & -0.5611 & 1.0000 & -0.3636 & -0.1950 \\
\hline$\Delta n_{t}$ & 0.1083 & -0.3636 & 1.0000 & 0.8960 \\
\hline$\Delta n s_{t}$ & 0.3320 & -0.1950 & 0.8960 & 1.0000 \\
\hline \multicolumn{5}{|c|}{ Regime 2: correlation } \\
\hline$\Delta y_{t}$ & 1.0000 & -0.0815 & 0.4130 & 0.1708 \\
\hline$\Delta w p_{t}$ & -0.0815 & 1.0000 & -0.2838 & -0.4113 \\
\hline$\Delta n_{t}$ & 0.4130 & -0.2838 & 1.0000 & 0.8672 \\
\hline$\Delta n s$ & 0.1708 & -0.4113 & 0.8672 & 1.0000 \\
\hline \multicolumn{5}{|c|}{ Regime 3: correlation } \\
\hline$\Delta y_{t}$ & 1.0000 & 0.7523 & 0.3359 & 0.1176 \\
\hline$\Delta w p_{t}$ & 0.7523 & 1.0000 & 0.0766 & -0.3430 \\
\hline$\Delta n_{t}$ & 0.3359 & 0.0766 & 1.0000 & 0.8552 \\
\hline$\Delta n s_{t}$ & 0.1176 & -0.3430 & 0.8552 & 1.0000 \\
\hline Fitting & MS-VECM & linear VECM & MS-DVAR & linear DVAR \\
\hline $\log \operatorname{Lik}$ & 1771.6512 & 1696.0655 & 1756.4101 & 1690.7240 \\
\hline AIC & -30.8720 & -30.0947 & -30.4520 & -29.8653 \\
\hline HQ & -29.6568 & -29.2238 & -29.3243 & -29.0798 \\
\hline $\mathrm{SC}$ & -27.8744 & -27.9464 & -27.6706 & -27.9282 \\
\hline
\end{tabular}


$\operatorname{VECM}(4)$ against the MSIH(3)-VECM(4) $(L R(24)=149.70)$ strongly rejects the linearity hypothesis, even when the upper bound of Davies (1977) is invoked. Further, the AIC and the HQ criterion favour of the non-linear VECM. Finally we note that the estimated adjustment coefficients have barely changed between the $\operatorname{VECM}(5)$ and the MSIH(3)-VECM(4), which lends support to the two-stage procedure.
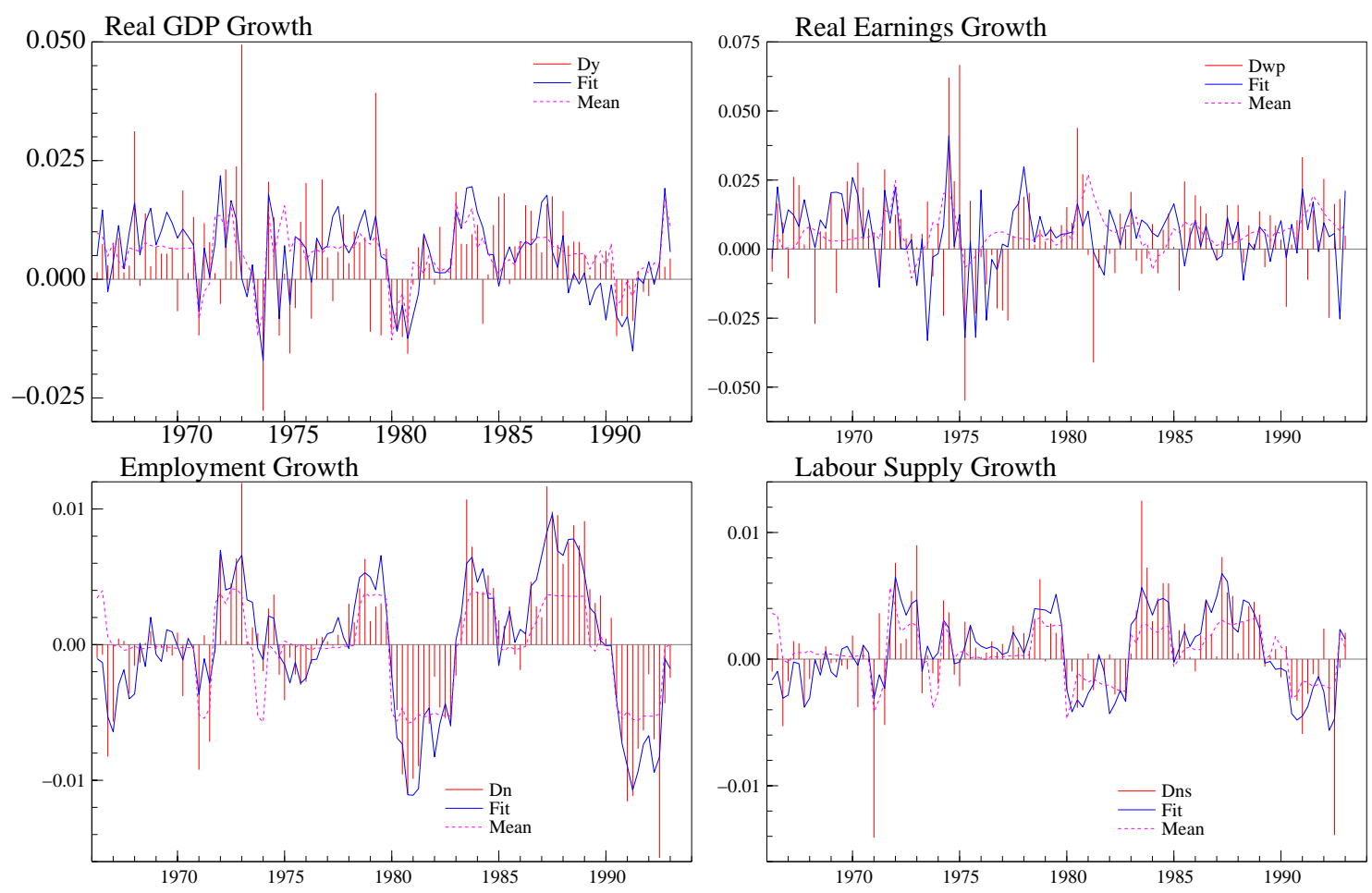

Figure 3 Fit of the MSIH(3)-VECM(4) model.

Additional evidence in favour of the MSIH(3)-VECM(4) is provided in Figure 3 where the fit of the model is good, and in Figures 4 and 5 which show the residuals to be non-correlated, homoskedastic, and normally distributed. Thus the regime inference of our model is based on a congruent econometric model of the UK labour market. As the regime inference is a by-product of the parameter estimation of the MS-VECM, our model overcomes the problems in Acemoglu and Scott (1994) where conditional models of employment dynamics in the UK are considered but the probability of a recession is derived from a non-congruent Markov-switching model of UK output growth.

\section{Forecasting Performance}

From the results we obtained so far, the MS-VECM appears to provide a good representation for the in-sample behaviour of output, real wage and employment, and a significant improvement with respect to standard linear specifications - see the statistics on model fit in Table 4. We now evaluate whether the MSIH model performs as well out of sample.

Krolzig (1998b) developed a general approach to predict multiple time series subject to Markovian shifts in the regime. Consider the $\operatorname{MS}(M)-\operatorname{VECM}(p-1)$ model

$$
\Delta \mathbf{x}_{t}=\mathbf{M} \xi_{t}+\alpha \beta^{\prime} \mathbf{x}_{t-1}-\alpha \gamma+\sum_{k=1}^{p-1} \Gamma_{k} \Delta \mathbf{x}_{t-k}+\mathbf{u}_{t}
$$



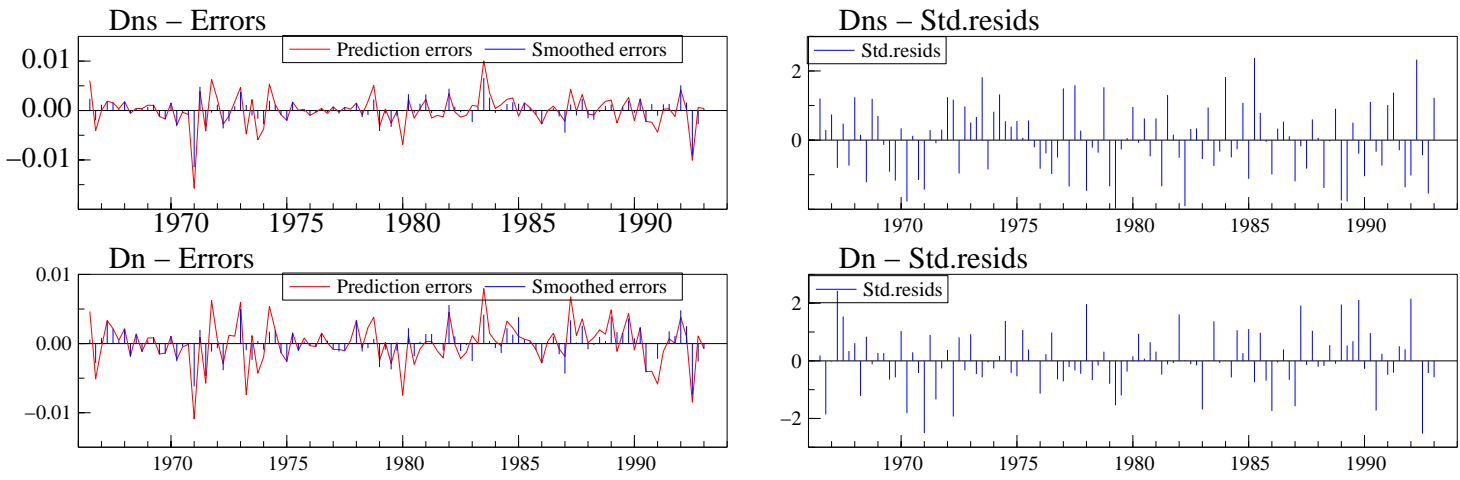

Dn - Std.resids
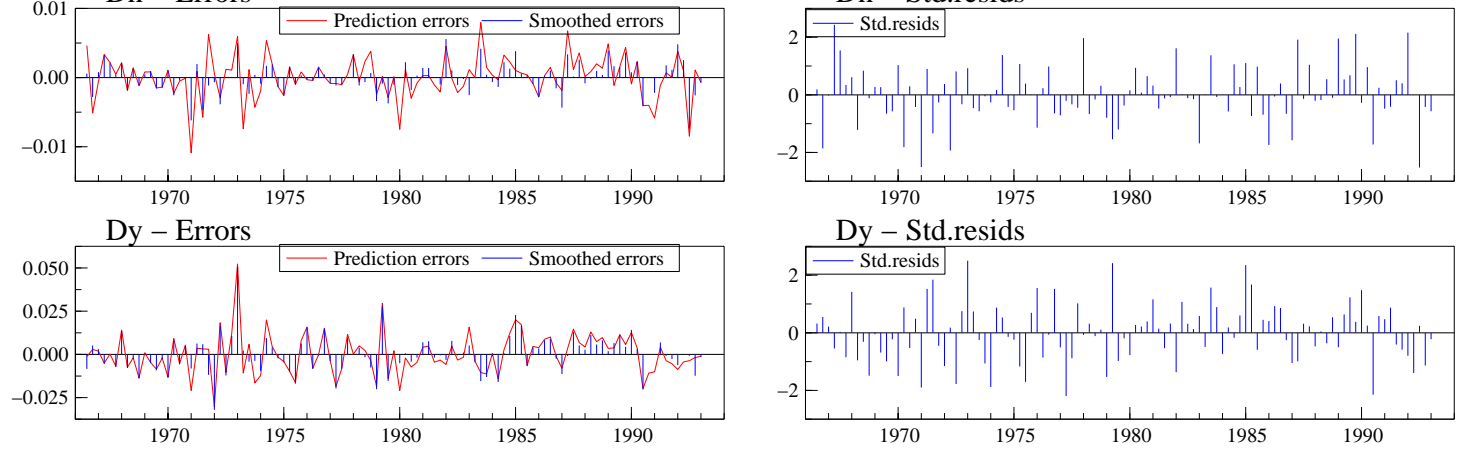

Dy - Std.resids
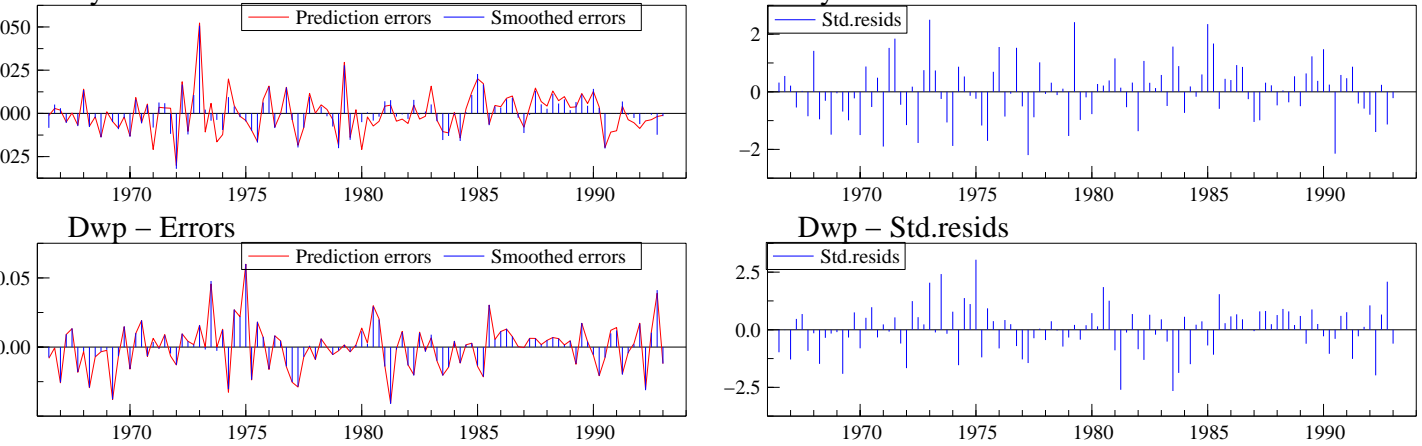

Figure 4 Residuals of the MSIH(3)-VECM(4) model.
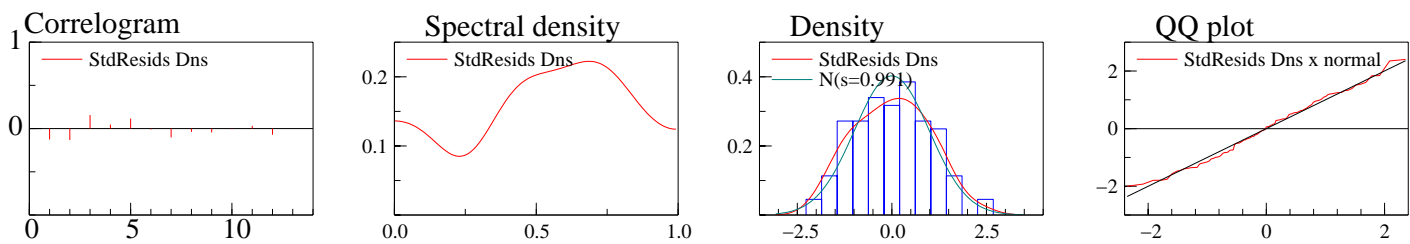

${ }_{1}$ Correlogram

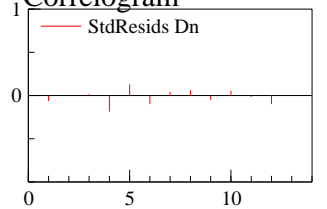

Spectral density

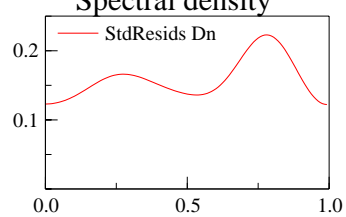

Density

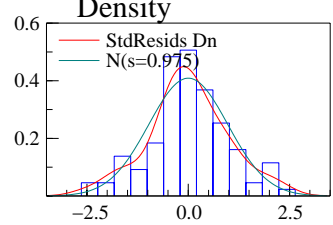

QQ plot

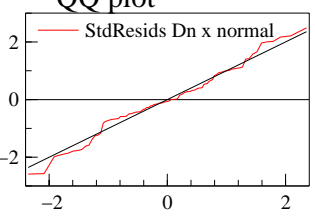

Correlogram

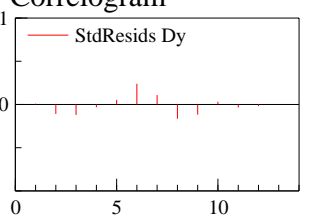

Spectral density

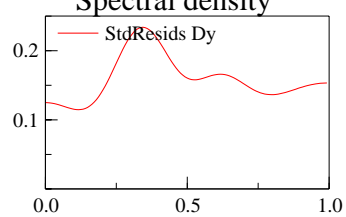

Density

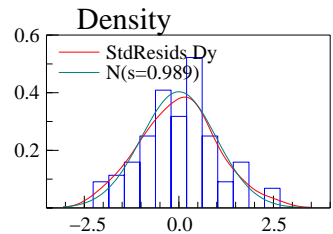

QQ plot

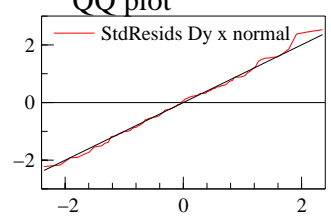

Spectral density

Correlogram
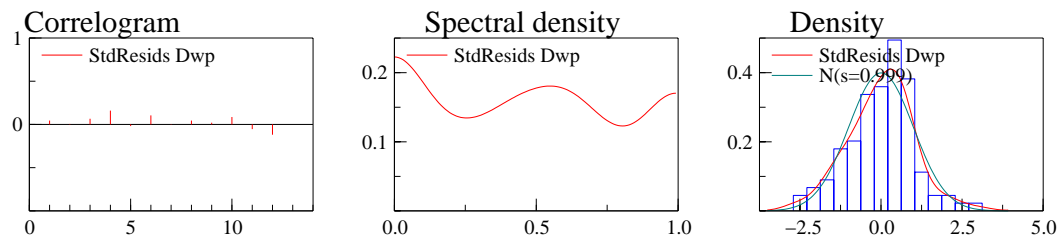

QQ plot

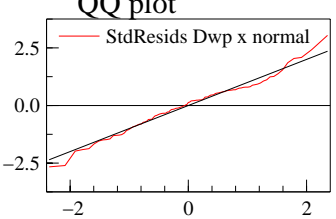

Figure 5 Statistical properties of the smoothed and predicted errors. 
where $\mathbf{M}=\left[\nu_{1}: \cdots: \nu_{M}\right]$ and $\xi_{t}$ is the $M$-dimensional state vector consisting of indicator variables $I\left(s_{t}=i\right)=1$ for $s_{t}=i$ and 0 otherwise. The one-step predictor can be derived from the corresponding $\operatorname{MSIH}(M)-\operatorname{VAR}(p)$ representation given by

$$
\mathbf{x}_{t}=\mathbf{M} \xi_{t}-\alpha \gamma(t-1)+\sum_{k=1}^{p} A_{k} \mathbf{x}_{t-k}+u_{t}
$$

where $A_{1}=\mathrm{I}_{N}+\alpha \beta^{\prime}+\Gamma_{1}$ and $A_{j}=\Gamma_{j}-\Gamma_{j-1}$ for $1<j \leq p$ with $\Gamma_{p}=\mathbf{0}_{K}$. Hence we have that

$$
\mathrm{E}\left[\mathbf{x}_{t+1} \mid \mathbf{x}_{t}, \ldots, \mathbf{x}_{0}\right]=\mathbf{M P} \hat{\xi}_{t \mid t}-\alpha \gamma t+\sum_{k=1}^{p} A_{k} \mathbf{x}_{t+1-k}
$$

where $\mathbf{P}$ is the transition matrix and $\hat{\xi}_{t \mid t}$ is the vector of filtered regime probabilities at time $t$. The predictor for the MSIH(3)-DVAR(4) model follows from (13) by setting $\alpha=0$.

We compare 5 models: the MS-VECM and its linear version, VECM, plus an MS and a standard VAR in first differences, MS-DVAR and DVAR, respectively. The final model considered is a VAR in the second differences of variables (DDVAR), which is a forecasting device that exploits the fact that very few variables accelerate/decelerate indefinitely. In fact, DVARs and DDVARs can provide good forecasts during periods of structural changes, in particular when there are shifts in equilibrium means and mean growth rates - see Clements and Hendry (1999) for a general exposition and Marcellino and Mizon (2000b) for an example relative to the Italian labour market.

The models are compared on the basis of the root mean square and absolute prediction errors, RMSPE and MAPE. The forecast period is 1991(2)-1993(1), for a total of 8 quarters. This choice leaves a sufficiently long estimation period to guarantee structural stability of the MS-VECM as a business cycle model, reasonable long-run properties, and strong convergence of the EM estimation procedure. ${ }^{1}$

Table 5 One-Step Prediction Errors 1991 (2) - 1993 (1).

\begin{tabular}{crrrr}
\hline \hline & $y$ & $w p$ & $n$ & $n s$ \\
\hline$M A P E\left(\times 10^{2}\right)$ & & & & \\
MSI(3)-VECM(4) & 0.60 & 1.70 & 0.26 & 0.29 \\
MSI(3)-DVAR(4) & 0.74 & 1.89 & 0.31 & 0.35 \\
Linear VECM(4) & 0.74 & 1.78 & 0.30 & 0.33 \\
Linear DVAR(4) & 0.75 & 1.96 & 0.34 & 0.36 \\
DDVAR(3) & 0.56 & 1.51 & 0.40 & 0.37 \\
$R M S P E\left(\times 10^{2}\right)$ & & & & \\
MSI(3)-VECM(4) & 0.80 & 2.05 & 0.37 & 0.43 \\
MSI(3)-DVAR(4) & 0.92 & 2.11 & 0.47 & 0.53 \\
Linear VECM(4) & 0.94 & 2.06 & 0.44 & 0.49 \\
Linear DVAR(4) & 0.99 & 2.18 & 0.49 & 0.53 \\
DDVAR(3) & 0.67 & 1.67 & 0.52 & 0.54 \\
\hline \hline
\end{tabular}

Table 5 reports the mean absolute prediction error (MAPE) and root mean squared prediction error (RMSPE) of one-step prediction errors for 1991(2) - 1993(1). It compares the MSI(3)-VECM(4) estimated from 1966(3) - 1991(1) with an MSI(3)-DVAR(4), linear VECM(4), DVAR(4) and DDVAR(3). From Table 5 it is evident that the MSI(3)-VECM(4) performs well, having the best RMSPE and of MAPE for $n$ and $n s$. Further, even though the DDVAR performs best for $w p$ and $y$, on average across all four variables there is very little between the MAPE and RMSPE for the MSI(3)-VECM(4) and the

\footnotetext{
${ }^{1}$ The regime classification of the full-sample MSIH(3)-VECM(4) was consistent with the sub-sample MSI(3)-VECM(4), but not with the subsample MSIH(3)-VECM(4); so the MSI(3)-VECM(4) has been chosen for the forecast evaluation.
} 
DDVAR(3). However, the DDVAR is forecasting device with few economic insights, whereas the MSVECM has economically interpretable equilibria and regimes shifts that are closely related to changes in the phases of the UK business cycle. Moreover, the fact that the VECM ranks third in forecasting performance, followed by the MS-DVAR, and the DVAR, has a number of implications. Firstly, the fact that the VECM forecasts better than either model in first differences suggest that there are advantages to using estimated equilibria in generating forecasts in this case. Secondly, the fact that the MSIH-VECM and the DDVAR forecast better than the VECM indicates that there have been changes in the intercepts, and hence in the means of the equilibria and in the stochastic trends. Indeed, this further suggests that the major change has been in the stochastic trends rather than the means of the equilibria, since changes in the latter would result in the VECM suffering forecast failure.

\section{Impulse-Response Analysis}

In this section we analyze the dynamic properties of the MSIH-VAR underlying the MSIH-VECM by calculating the impulse response functions (IRF). First we compare the results for the MSIH-VAR and a linear VAR. We then show that the differences reported in sub-section 6.1 are essentially replicated when Choleski decompositions for various orderings of the variables are used. Finally, we follow the approach in Krolzig and Toro (1998) to evaluate changes in the MSIH-VAR responses across regimes.

\subsection{MSIH-VAR and VAR}

In figure 6 we compare the results for the MSIH-VAR and a standard VAR. Standard IRFs are calculated for one standard deviation impulses to the innovations for each of the variables, without orthogonalizing the variables. We do this both for simplicity and because we want to focus on possible differences in the responses between models and across regimes.

The shape and timing of the responses to a one standard deviation impulse to output innovation are similar for the two models, with a slightly stronger positive impact on $y$ itself and a milder effect on $w p$ in the MSIH-VAR: when $y$ increases, $w p$ and $n$ also increase, but with a certain delay. The increase in output is permanent and it is associated to a long run increase of the same magnitude in $n$. This implies that the long run response of $y-n$, i.e. of productivity, is close to zero, which is coherent with the equilibrium in (8). The long run response of $w p$ is also zero, which is in agreement with the other equilibrium in (9). This finding holds both for the MSIH-VAR and for the standard VAR, and it is present in the responses to all the other shocks, see Figure 6. Hence, the MS properties do not affect the long run relationships across the variables, and this provides further evidence in favour of the two-stage estimation procedure we adopted in section 4.

The responses to a standard deviation impulse in the real wage innovation are very similar for the MSIH-VAR and the VAR. Output and employment decrease, also in the long run, and the real wage quickly decreases. The fact that $n$ decreases more than the labour force suggests that unemployment would increase.

The major differences between the MSIH-VAR and the VAR are in the responses to shocks to $n$ and to $n s$. In particular, the short run effects of a positive impulse to $n$ on $y$ and $n$ are positive according to the VAR and negative for the MSIH-VAR. Then, $y$ and $n$ decrease also in the VAR, but the final effects remain positive, while they are negative in the MSIH-VAR. In both cases, the reaction of $n s$ is negative and such that unemployment would decrease. When instead there is a positive shock to the labour force, the effects are permanent, actually increasing over time, both in the MSIH-VAR and in the VAR. Yet, in the MSIH-VAR, employment increases, output as well, after an initial slight decrease, and 

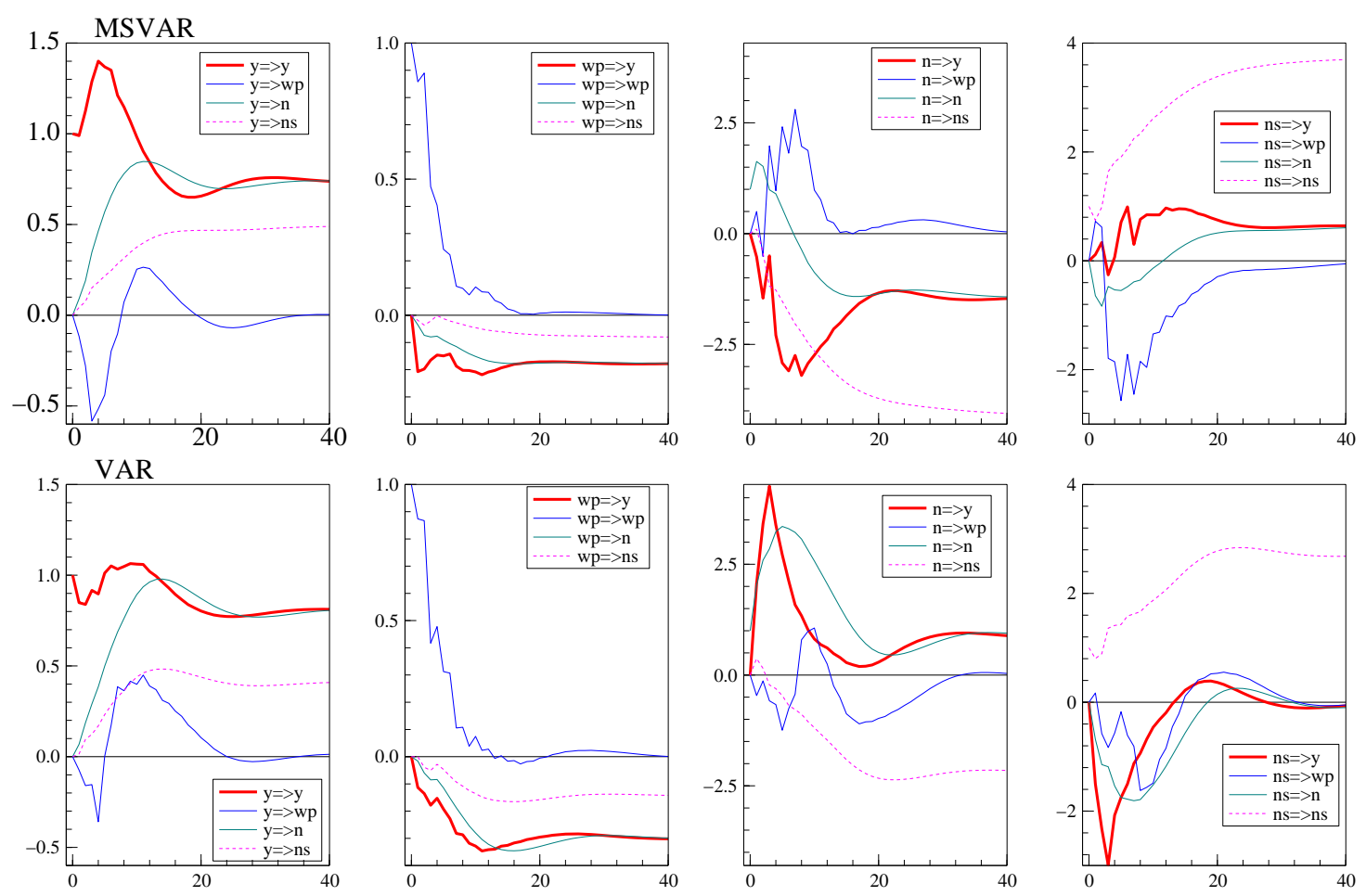

Figure 6 Impulse Response Functions, MS-VAR and standard VAR.

real wages have a u-shaped response. Instead, in the VAR, $y$ and $n$ are strongly and negatively affected in the short run, with basically no effects in the long run. In both cases unemployment would increase, but the responses from the MSIH-VAR appear to be more sensible from an economic point of view.

In summary, the IRF from the MSIH-VAR and the standard VAR are coherent with the results from the cointegration analysis and differ mainly for the responses to shocks in employment and the labour force. We might expect the differences to emerge also with orthogonalizing the residuals. Yet, these results should be interpreted with care because, from the previous section, the covariance matrix of the error term is regime dependent, so that orthogonalized IRFs will differ across regimes. In the next subsection we evaluate whether this is the case.

\subsection{Keynesian and Classical Orthogonalizations}

We consider two alternative orderings of the variables: $y$-n-wp-ns and $n s-n-y-w p$. The former can be related to a standard Keynesian model where increased demand leads to increased production, which requires an increase in labour demand. Unemployment falls as only a part of the employment growth is sustained by an increased labour force participation. As nominal wages tend to be more sluggish than prices, the real wage falls initially, over time wages adjust to the increased level of labour productivity The latter ordering is more in line with a classical world, where changes in the labour supply drive labour input and production, which in turn affects the real wage.

Analyzing orthogonalized IRFs is standard in the case of linear VARs (see, inter alia, Hamilton, 1994, §11.4). For the MSIH-VECM proposed in section 4, the presence of regime-dependent heteroskedasticity requires special attention: As the covariance matrix of the error term is regime dependent, so are its Choleski decompositions and the associated orthogonalized impulses. Thus for each of the two orderings of the variables, we get three IRFs describing the response of the variables dependend on 

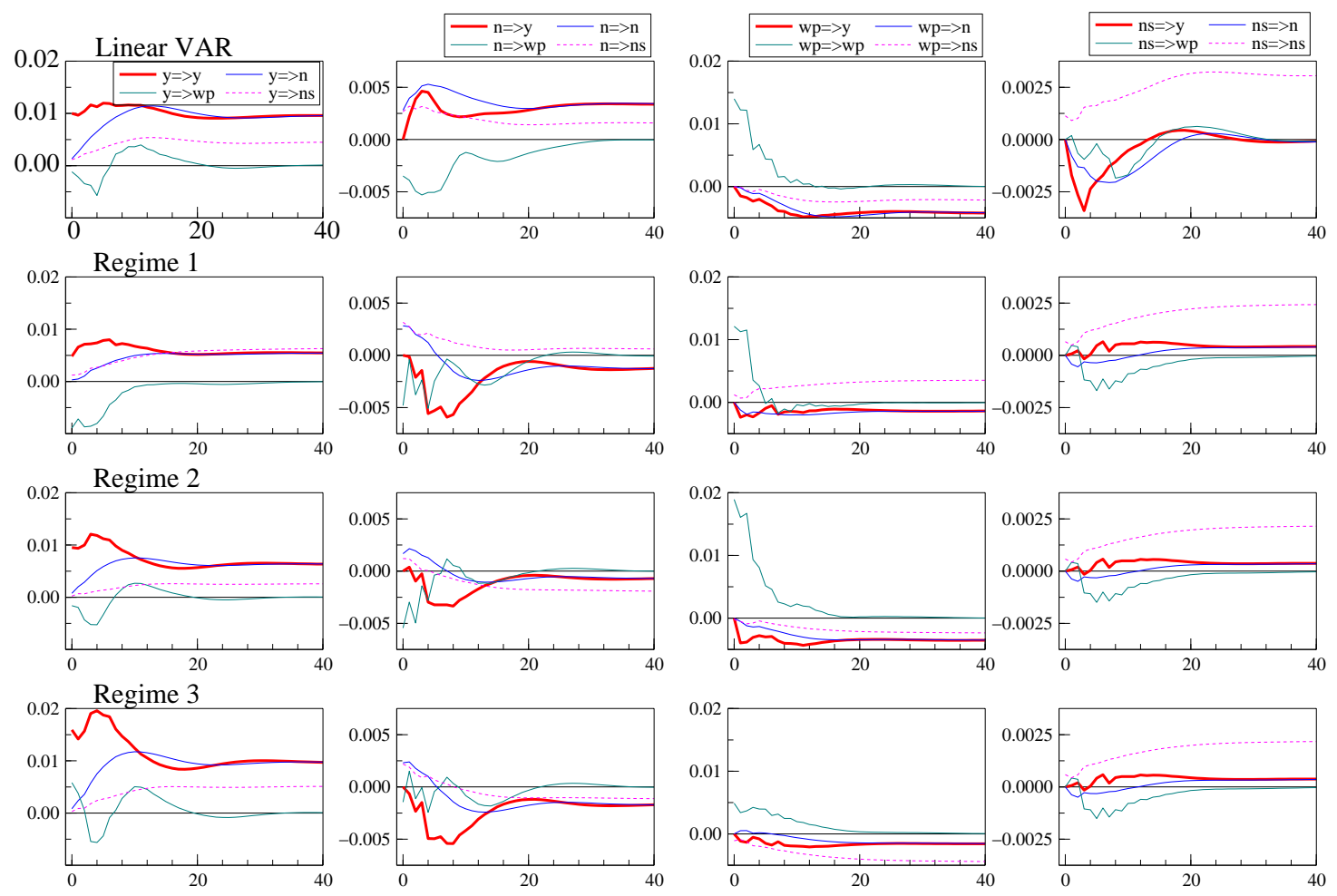

Figure 7 Impulse Response Functions: Keynesian Orthogonalization.

the state of the system when the shock occurs.

Starting with the Keynesian ordering, the main difference across regimes to a shock to the $y$ equation error appears to be in the response of $w p$. In a recession only a prolonged increase in $y$ increases $w p$; in the other regimes $w p$ has an obscillatory behaviour, with an early drop related to an increase in $n$ more than proportional to that in $n s$. The reactions to a shock in $w p$ are rather limited and similar in all three regimes. Note in particular that there is never a positive long run effect on productivity, though one results from the linear VAR. A shock in the $n$ equation error is associated with an increase in $n s$ during a recession, while $n s$ decreases in the other cases. Also, $w p$ appears to increase, less so in an expansion, and in any case only for few periods. Finally, a shock to $n s$ has similar effects across the three regimes, but is less marked than in the linear VAR.

Turning to the classical ordering, the response to a shock in $y$ are similar to the former case, as well as those to a shock in $n s$, with the exception of regime 2 . The response of real wages to positive output shocks strongly varies across the regimes: they behave anticyclical in recessions (regime 1) and procyclical in expansions (regime 3). The effects of an impulse to $w p$ are instead much more limited, and more evident in the second regime. The reaction of the variables to an impulse in $n$ are also rather different from before, both in the timing and in the magnitude and in the long run effects.

In summary, the most relevant results for our goal are the substantial differences in the IRF that emerge across regimes and with respect to the linear VAR, independently of the chosen orthogonalization. In the next subsection we explore an alternative approach to analyze the source and propagation of shocks. 

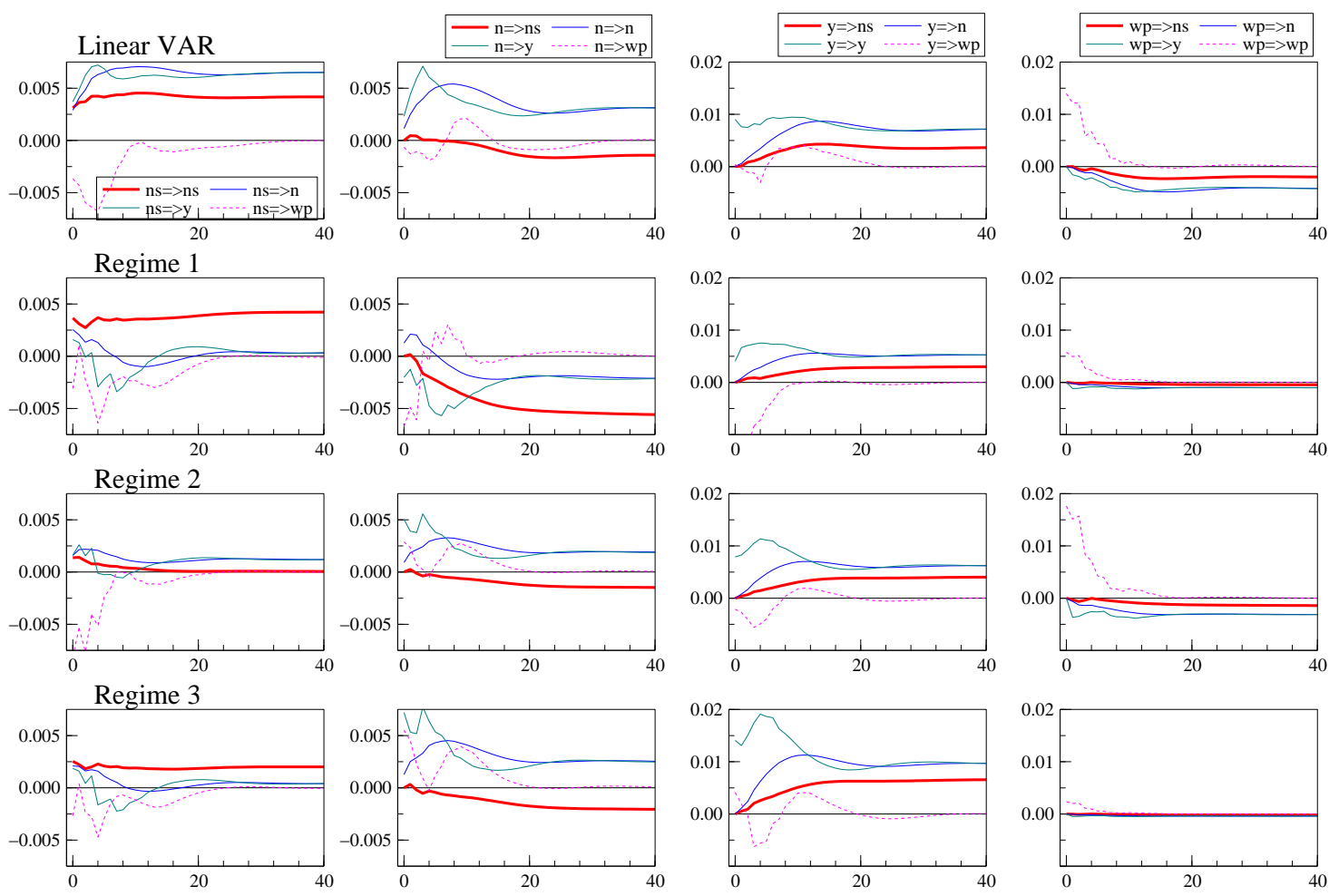

Figure 8 Impulse Response Functions: Classical Orthogonalization.

\subsection{IRF of regime shifts}

Standard IRF analysis focuses on the response of the system to Gaussian innovations, but other shocks could affect the system. In particular, changes in the phase of the cycle is what some economists have in mind when they refer to 'cyclical shocks', namely, investigating the dynamics of some variables in the transition from boom to bust, or vice versa. Within the MSIH-VAR framework, we can deal with both types of shocks.

The impulse responses with respect to transitions of the state variables depend on the properties of the VAR, combined with those of the hidden Markov chain. In fact, these effects are due to: (i) changes in the current state and hence changes to the conditional expectation of a future regime; and (ii) the autoregressive transmission of intercept shifts. A formal mathematical derivation of these responses is presented in the appendix of Krolzig and Toro (1998).

In Figure 9 we characterize the behaviour of the variables for the system for each of the three regimes when compared to the ergodic regime probability distribution, and present the responses to changes in the phase of the cycle. A first characteristic that emerges from the IRF on the diagonal of Figure 9 is that the long run responses of $y-n$ and $w p$ remain close to zero across all the three regimes, providing additional evidence in favour of the cointegration results. Yet, the responses are different across regimes: in a recession, both $y$ and $n$ react negatively; in a period of normal growth the response is similar and positive; while during an expansion $y$ reacts more than $n$ in the short run. This asymmetric behaviour of $n$ and $y$ can be given a theoretical rationale - see Krolzig and Toro (1998) for an overview of some theoretical models. Another sensible result is that the combined effect of the shocks on $n$ and $n s$ is such that unemployment would increase in a recession and decrease during a phase of normal or strong growth.

Consider now the path taken by the variables when there is a change in regime. We observe that 

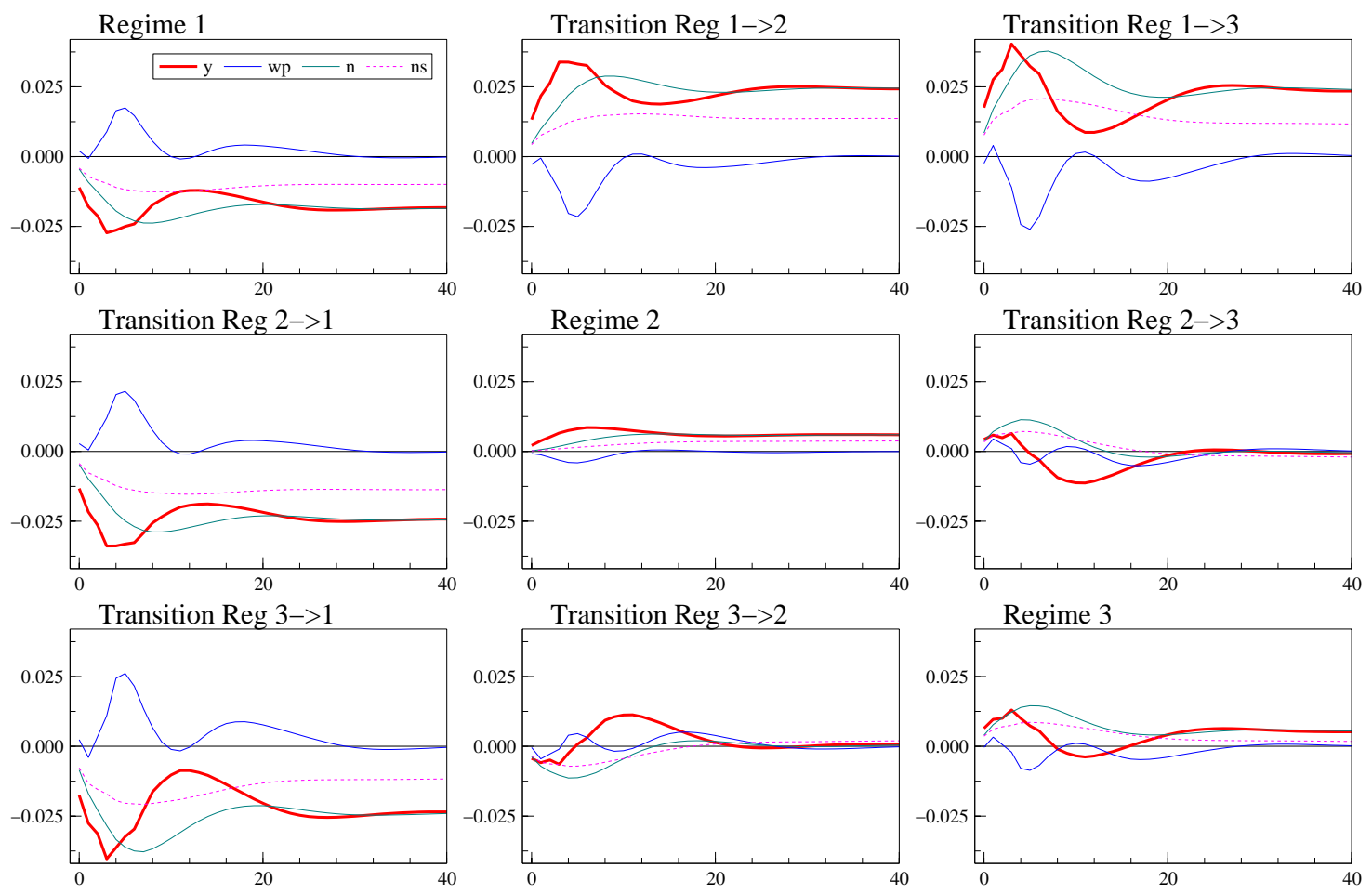

Figure 9 The Response of the System after Shifts in Regime.

moving from a recession to a period of normal or of high growth leads to a similar behaviour of the variables: $y, n$ and $n s$ react positively and in a permanent manner to the shocks, while $w p$ temporarily decreases. Instead, the transitions from a high growth period to a normal period or to a recession are different. In the former case there are smaller fluctuations, $y$ tending to increase and $n$ to decrease in the short run, while in the long run all the effects are close to zero. In the latter, both $y$ and $n$ tend to decrease both in the short and in the long run, while the real wage increases in the short run. Finally, the transition from normal growth to recession is similar to that from high growth, while the impact of moving to high growth is the mirror image (but with negative coefficients) of the response of the variables to a change from high to normal growth. Note that in our model the mean and variance of the process are state-dependent, but the autoregressive parameters are constant across regimes. Hence, the responses to a change from regime two to regime one (say) is the mirror image (but with negative coefficients) of the response of the variables to a change from regime one to regime two.

\section{Conclusions}

In this paper we have estimated an MSIH-VECM for a small set of UK labour market variables, and found that it provides a good characterization of the sample data over the period 1966(3)-1993(1) despite there having been many changes affecting this sector of the UK economy. In addition, the switches between the three regimes are closely related to changes in the phases of the UK business cycle. Reassuringly, the MSIH-VECM forecasts better than the VECM and models involving first differences of variables, thus indicating the importance of representing some of the changes. Indeed, the possibility that the MS property can improve forecasting performance has been illustrated in our analysis of a small model model of the UK labour market. The only serious competitor in forecasting was the VAR 
in second differences, which though a useful forecasting device for non-stationary data, has limited economic interpretation and few economic implications. Having found evidence for the existence of three separate regimes the results in this paper also highlight the dangers of using impulse response analysis for VARs when the constancy of the estimated coefficients has not been established. This supports the arguments in Ericsson, Hendry and Mizon (1998) and Hendry and Mizon (2000) that great care is needed in using and interpreting impulse response functions.

\section{References}

Acemoglu, D., and Scott, A. (1994). Asymmetries in the cyclical behaviour of UK labour markets. Economic Journal, 104, 1303-1323.

Chow, G. C. (1960). Tests of equality between sets of coefficients in two linear regressions. Econometrica, 28, 591-605.

Clements, M. P., and Hendry, D. F. (1999). Forecasting Non-Stationary Economic Time Series. Cambridge, Mass.: MIT Press. The Zeuthen Lectures on Economic Forecasting.

Clements, M. P., and Mizon, G. E. (1991). Empirical analysis of macroeconomic time series. VAR and structural models. European Economic Review, 35, 887-932.

Cooper, R., and John, A. (1988). Coordinating coordination failures in Keynesian models. Quarterly Journal of Economics, 103, 441-463.

Davies, R. B. (1977). Hypothesis testing when a nuisance parameter is present only under the alternative. Biometrika, 64, 247-254.

Doornik, J. A. (1999). Object-Oriented Matrix Programming using Ox. London: Timberlake Consultants. 3rd edn.

Ericsson, N. R., Hendry, D. F., and Mizon, G. E. (1998). Exogeneity, cointegration and economic policy analysis. Journal of Business and Economic Statistics, 16, 370-387.

Gonzalo, J., and Granger, C. (1995). Estimation of common long memory components in cointegrated systems. Journal of Business and Economic Statistics, 13, 27-35.

Hall, S. G. (1986). An application of the Granger and Engle two step estimation procedure to United Kingdom aggregate wage data. Oxford Bulletin of Economics and Statistics, 48, 213-228.

Hall, S. G. (1989). Maximum likelihood estimation of cointegrating vectors. Oxford Bulletin of Economics and Statistics, 51, 213-218.

Hall, S. G., and Henry, S. G. B. (1987). Wage models. National Institute Economic Review, 0(119), 91-112.

Hamilton, J. D. (1989). A new approach to the economic analysis of nonstationary time series and the business cycle. Econometrica, 57, 357-384.

Hamilton, J. D. (1990). Analysis of time series subject to changes in regime. Journal of Econometrics, 45, 39-70.

Hamilton, J. D. (1994). State-space models. In Engle, R., and McFadden, D. (eds.), Handbook of Econometrics, Vol. 4. Amsterdam: North-Holland.

Hendry, D. F., and Mizon, G. E. (2000). Reformulating empirical macro-econometric modelling. Oxford Review of Economic Policy, ?, ???-??? Forthcoming.

Johansen, S. (1995). Likelihood-Based Inference in Cointegrated Vector Autoregressive Models. Oxford: Oxford University Press. 
Krolzig, H.-M. (1996). Statistical analysis of cointegrated VAR processes with Markovian regime shifts. SFB 373 Discussion Paper 25/1996, Humboldt Universität zu Berlin.

Krolzig, H.-M. (1997). Markov Switching Vector Autoregressions. Modelling, Statistical Inference and Application to Business Cycle Analysis. Berlin: Springer.

Krolzig, H.-M. (1998a). Econometric modelling of Markov-switching vector autoregressions using MSVAR for Ox. Discussion paper, Institute of Economics and Statistics, University of Oxford: http://www.econ.ox.ac.uk/research/hendry/krolzig.

Krolzig, H.-M. (1998b). Predicting Markov-switching vector autoregressive processes. Discussion paper, Institute of Economics and Statistics, University of Oxford.

Krolzig, H.-M., and Sensier, M. (2000). A disaggregated Markov-switching model of the UK business cycle. Manchester School, 68, 442-460.

Krolzig, H.-M., and Toro, J. (1998). A new approach to the analysis of shocks and the cycle in a model of output and employment. Working paper eco 99/30, EUI, Florence.

Marcellino, M., and Mizon, G. E. (2000a). Modelling shifts in the wage-price and unemploymentinflation relationships in Italy, Poland, and the UK. Economic Modelling, 17, 387-413.

Marcellino, M., and Mizon, G. E. (2000b). Small system modelling of real wages, inflation, unemployment and output per capita in Italy 1970-1994. mimeo., Economics Department, Southampton University.

Mizon, G. E. (1995). Progressive modelling of macroeconomic time series: the LSE methodology. In Hoover, K. D. (ed.), Macroeconometrics: Developments, Tensions and Prospects, pp. 107-169. Dordrecht: Kluwer Academic Press.

Sargan, J. D. (1964). Wages and prices in the United Kingdom: A study in econometric methodology (with discussion). In Hart, P. E., Mills, G., and Whitaker, J. K. (eds.), Econometric Analysis for National Economic Planning, Vol. 16 of Colston Papers, pp. 25-63. London: Butterworth Co. Reprinted as pp. 275-314 in Hendry D. F. and Wallis K. F. (eds.) (1984). Econometrics and Quantitative Economics. Oxford: Basil Blackwell, and as pp. 124-169 in Sargan J. D. (1988), Contributions to Econometrics, Vol. 1, Cambridge: Cambridge University Press. 